\title{
Attitudes and perceptions of Sudanese high-school students and their parents towards spectacle wear
}

\begin{tabular}{|c|c|}
\hline \multicolumn{2}{|c|}{$\begin{array}{l}\text { Authors: } \\
\text { Saif H. Alrasheed }{ }^{1,2} \\
\text { Kovin S. Naidoo }{ }^{2,3} \\
\text { Peter C. Clarke-Farr }\end{array}$} \\
\hline \multicolumn{2}{|c|}{$\begin{array}{l}\text { Affiliations: } \\
{ }^{1} \text { Faculty of Optometry and } \\
\text { Visual Science, AI Neelain } \\
\text { University, Sudan }\end{array}$} \\
\hline \multicolumn{2}{|c|}{$\begin{array}{l}{ }^{2} \text { African Vision Research } \\
\text { Institute, University of } \\
\text { KwaZulu-Natal, South Africa }\end{array}$} \\
\hline \multicolumn{2}{|c|}{$\begin{array}{l}{ }^{3} \text { Brien Holden Vision } \\
\text { Institute, Sydney, Australia }\end{array}$} \\
\hline \multicolumn{2}{|c|}{$\begin{array}{l}{ }^{4} \text { Department of Ophthalmic } \\
\text { Sciences, Cape Peninsula } \\
\text { University of Technology, } \\
\text { South Africa }\end{array}$} \\
\hline \multicolumn{2}{|c|}{$\begin{array}{l}\text { Corresponding author: } \\
\text { Saif Alrasheed, } \\
\text { saif.alrasheed@yahoo.com }\end{array}$} \\
\hline \multicolumn{2}{|c|}{$\begin{array}{l}\text { Received: } 24 \text { Feb. } 2017 \\
\text { Accepted: } 08 \text { Dec. } 2017 \\
\text { Published: } 11 \text { Apr. } 2018\end{array}$} \\
\hline \multicolumn{2}{|c|}{$\begin{array}{l}\text { How to cite this article: } \\
\text { Alrasheed SH, Naidoo KS, } \\
\text { Clarke-Farr PC. Attitudes and } \\
\text { perceptions of Sudanese } \\
\text { high-school students and } \\
\text { their parents towards } \\
\text { spectacle wear. Afr Vision } \\
\text { Eye Health. 2018;77(1), a392 } \\
\text { https://doi.org/10.4102/ } \\
\text { aveh.v77i1.392 }\end{array}$} \\
\hline \multicolumn{2}{|c|}{$\begin{array}{l}\text { Copyright: } \\
\text { (c) 2018. The Author(s). } \\
\text { Licensee: AOSIS. This work } \\
\text { is licensed under the } \\
\text { Creative Commons } \\
\text { Attribution License. }\end{array}$} \\
\hline \multirow[b]{2}{*}{ 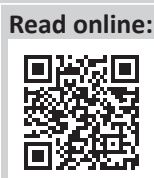 } & \\
\hline & $\begin{array}{l}\text { Scan this QR } \\
\text { code with your } \\
\text { smart phone or } \\
\text { mobile device } \\
\text { to read online. }\end{array}$ \\
\hline
\end{tabular}

Background: Uncorrected refractive error is a major cause of avoidable vision impairment and may have significant impact on social life, education and economic prospects of people. This condition could be easily treated by wearing spectacles, but because of attitudes and misconceptions of some communities towards spectacle wear and eye care, such methods are underutilised.

Aim: To assess the attitudes and perceptions of Sudanese high-school students and their parents towards spectacle wear.

Setting: The study was conducted in eight randomly selected high schools from the South Darfur state of Sudan.

Methods: A cross-sectional school-based study comprising 387 high-school students with age ranging from 12 to 17 years together with 47 students' parents with age ranging from 32 to 52 years. Quantitative and qualitative methods were used to collect data from eight high schools. Semi-structured questionnaires were distributed to collect the quantitative data, and seven focus group meetings were held in the schools with students' parents to derive the qualitative data.

Results: The findings revealed that $39 \%, 32 \%$ and $27.1 \%$ of the students believed that wearing spectacles affected their opportunities for education, employment and marriage, respectively. A total of $36.4 \%$ of the students believed that wearing spectacles could lead to making the eyes weaker or could damage the eyes, resulting in early blindness, and $22.5 \%$ of the respondents believed that spectacles were only for older people. In general, the perception towards spectacle wear was different between genders, with females appearing to be more vulnerable to social and psychological distress when wearing spectacles compared to males. A total of $79 \%$ of the parents were aware that wearing spectacles would improve vision if an eye doctor prescribed the spectacles. However, parents reported that the disadvantages of wearing spectacles were that they reduced the power of the eyes and spectacle wear had psychological effects, particularly among females. Parents felt that their children had lost an important asset, that the community looked at them as handicapped and that their children would be blind in future.

Conclusion: The fear and stigma related to the use of spectacles are widely experienced among students and their parents in Sudan, and particularly among females. Eye health education programmes should be broadcast through the public media to promote awareness and benefits about spectacle wear and eye care.

\section{Introduction}

The World Health Organization reports that the major cause of global vision impairment is uncorrected refractive error and estimates that $80 \%$ of vision impairment is avoidable. ${ }^{1}$ Refractive error occurs when the eye does not focus light correctly onto the retina. ${ }^{2}$ There are three types of ametropia (refractive error), namely myopia, hypermetropia and astigmatism. It affects more than a third of the population, and although the exact cause of refractive error remains unknown, the common risk factors heredity, nutrition and the environment could lead to the development of refractive errors. ${ }^{2}$ Uncorrected refractive errors drive children and adults further into poverty by limiting their opportunities in education or employment, and could seriously affect their quality of life and productivity.,

Current data reveal that more than 2.3 billion people in the world have vision impairment because of uncorrected refractive error, and estimates are that more than $90 \%$ of them live in 
rural and developing nations., ${ }^{5,6}$ Recently, Holden et al. predicted that the prevalence of myopia worldwide would be $49.8 \%$ by 2050 .

It is clear that uncorrected refractive errors not only affect the social life and economic prospects of people as it is one of the major causes of vision impairment but also could have great impact on the psychological development of people. Uncorrected refractive error is the leading cause of vision impairment among children, ${ }^{9}$ that could easily be corrected by spectacles, which are the least expensive and most common optical method for correcting refractive error. ${ }^{10}$ Because of ignorance, stigmas, misconceptions and cost-related issues, this method, however, is underutilised. There have been a large number of studies on prevalence and distribution of refractive errors in school children worldwide, but there have only been a few studies conducted to understand the psychosocial impacts of and perceptions towards spectacle wear among school-aged children. ${ }^{8}$ Studies by Agarwal and Dhoble, ${ }^{8}$ Castanon Holguin et al. ${ }^{11}$ and Nyamai et al. ${ }^{12}$ indicated that the attitudes and perceptions towards spectacles were barriers for correcting refractive error among children.

The school-based study indicated that the prevalence of myopia, hypermetropia and astigmatism among Sudanese school-aged children is $6.8 \%, 1.9 \%$ and $2.5 \%$, respectively. ${ }^{13}$ Uncorrected refractive error is estimated to be the main cause of visual impairment among Sudanese school-aged children at $57 \% .{ }^{13}$ Eye health education plays an important role in reducing avoidable blindness as well as to help ensure a healthy and educated community. ${ }^{14}$ To date, no studies have been conducted to determine the attitude and perception towards spectacle use in high-school children in the South Darfur state of Sudan. This study focused specifically on young high-school children and their parents, because the attitudes and perceptions of these participants are critical to the success of interventions aimed at reducing vision impairment because of refractive error.

\section{Methods}

\section{Study design}

An observational cross-sectional school-based study consisting of semi-structured questionnaires as well as focus group discussion (FGD) methodology was employed for assessing the attitudes and perceptions towards spectacle wear and eye care.

\section{Setting}

The study was conducted in both public and private high schools in the South Darfur state of Sudan. The South Darfur state is located in the far south-west of Sudan, $1096 \mathrm{~km}$ away from the capital city, Khartoum. It is the second most populous state in Sudan (4.45 million people). ${ }^{15}$

Inclusion criteria consisted of students aged between 12 and 17 years as well as all parents who agreed to participate in the study. Exclusion criteria consisted of students aged younger than 12 years and older than 17 years. There were no exclusion criteria for the parents.

\section{Sample selection}

The sample size for the students was calculated by using the formula for estimating a single population proportion as follows:

$$
N=\frac{Z^{2} \times(P) \times(1-P)}{C^{2}}
$$

$Z=$ value of the $z$-statistic at the $95 \%$ confidence level $=1.96$, $P=$ estimated proportion of the outcome of the response assumed to be $50 \%$ of the students' attitudes and perceptions about spectacle wear and eye care for maximum sample size, $C=$ maximum acceptable sampling error $=4.70 \%$ or 0.047 in decimal notation:

$$
\frac{(1.96)^{2} \times(0.5) \times(1-0.5)}{(0.047)^{2}}=435
$$

This calculation resulted in a sample size of 435 students. Considering a $10 \%$ non-participant rate (44), the final sample size of this study was determined to be 479 students. The selection process firstly identified all public and private schools within 21 districts of South Darfur from a list of schools of the entire state obtained from the Ministry of Education. Thereafter, eight schools, four for males and four for females, were randomly selected from the list of 21 districts. The sampling frame consisted of a listing of the grade level within each school with the number of children in seventh and eighth grade classrooms. Finally, 60 students were randomly selected from each school. For the sample size for the parents, seven schools were randomly selected to carry out FGD with parents of high school-aged children. A total of 47 parents participated in the focus group ( 29 females and 18 males).

\section{Data collection}

A semi-structured questionnaire was developed based on the literature review in order to collect quantitative data from the students. ${ }^{8,10,11,12}$ The questions sought to gain insight into the students' attitudes and perceptions towards spectacle wear and eye care. The questionnaire had 15 statements that used a three-point Likert scale to measure attitudes and perceptions of high school-aged children towards spectacle wear and eye care. Prior to implementation, the questionnaire was evaluated by a sample of optometrists, ophthalmologists and eye care managers and then pretested with a pilot study, which was carried out with 50 students outside of the main research field. Data were gathered by a self-administered questionnaire in the classroom setting supervised by the principal investigator and research assistant.

For the qualitative process, a semi-structured guideline was developed to guide the discussions. The main consideration 
for the FGDs was to assess key concepts related to attitudes and perception towards spectacle wear and eye care. Three trained data collectors used the focus group guide in order to collect the data through the discussions which were conducted in the local language (Arabic) and then transcribed into English. The FGDs were audio recorded.

\section{Data analysis}

The quantitative data were analysed using the Statistical Package for the Social Sciences (SPSS), version 22. The data were checked for data entry errors and any missing values were entered before conducting the data analysis. Descriptive statistics were used to describe the data. Analysis of variance (ANOVA) was used for statistical comparison of means, and chi-squared tests were used to determine statistical significance. The qualitative data were analysed using transcript-based analyses. The focus group audiotapes were transcribed verbatim by the principal investigator and the information was cleaned by stripping non-essential words. For all statistical determinations, the significance level was established at $p<0.05$.

\section{Ethical considerations}

Ethical permission for conducting the study was obtained from the University of KwaZulu-Natal's Biomedical Research Ethics Committee (ref: BE247/14) and the National Research Ethics Review Committee in Sudan. Permission was also obtained from the South Darfur authorities in Sudan to undertake the research at their facilities. Informed consent was obtained from all participants included in the study, and assent was obtained from children to facilitate a better understanding of conditions for involvement in the study. The research was conducted in accordance with the Declaration of Helsinki.

\section{Results}

\section{Quantitative results}

\section{Study population}

A total of 479 students from eight selected schools (four male schools and four female schools) were invited to participate in the study. However, only 387 students returned completed questionnaires, giving a response rate of $81 \%$. In addition, 47 parents consisting of 29 females and 18 males participated in the focus groups. The focus groups ranged from five to eight people. The average group size was seven people. Thus, the results of 387 students and seven focus groups with 47 parents were analysed and represented as follows.

\section{Socio-demographic characteristics of participants}

The demographic characteristics of the high-school children are shown in Table 1. The sample consisted of 198 (51.2\%) females and 189 (48.8\%) males. The mean age and standard deviation (s.d.) of females and males was $14.15 \pm 1.27$ (s.d.)
TABLE 1: Distribution of the high-school children $(N=387)$ by demographic characteristics.

\begin{tabular}{lcc}
\hline Characteristics & $\boldsymbol{N}$ & $\%$ \\
\hline Gender & 189 & \\
Male & 198 & 48.8 \\
Female & & 51.2 \\
Age (in years) (mean $\mathbf{1 4 . 2 \pm \mathbf { 1 . 2 6 } )}$ & 26 & \\
12 & 87 & 6.7 \\
13 & 141 & 22.5 \\
14 & 80 & 36.4 \\
15 & 24 & 20.7 \\
16 & 29 & 6.2 \\
17 & & 7.5 \\
Grades & 153 & \\
Seventh & 234 & 39.5 \\
Eighth & & 60.5 \\
\hline
\end{tabular}

and $14.25 \pm 1.25$ (s.d.), respectively, whereas the mean age and s.d. of both was $14.20 \pm 1.26$. The differences between the mean ages of males and females were not significant (ANOVA $F=0.635, p=0.426$ ). The majority of respondents fell within either the 14 -year age group $(36.4 \%)$ or 13 -year age group $(22.5 \%)$, whereas the least number of participants were aged $16(6.2 \%)$. The majority of the respondents $(60.5 \%)$ were in grade 8 . In terms of the parents' education levels, $62.3 \%$ school children reported their parents have primary education, $28.2 \%$ reported their parents have secondary education and only $9.6 \%$ reported their parents have higher education.

The sample of the parents comprised 29 (61.7\%) females and $18(38.3 \%)$ males. Their ages ranged from 32 to 52 years, with an average age of 42 years and the largest group of participants (23.4\%) being $41-43$ years.

\section{Students' attitudes towards spectacle wear and eye care}

In this section, the students addressed a combination of positive and negative statements relating to their perceptions towards spectacle wear and eye care. To help in measuring their attitudes towards spectacle wear and eye care, a 3-point Likert scale was used, with options ranging from disagree to agree. This section contained 15 statements related to their attitudes and perceptions as shown in Table 2.

Overall, approximately 39\% of the students felt that wearing spectacles affected their opportunities in education (females $43.0 \%$ and males $33.9 \%$ ), and $40.8 \%$ of the students felt that wearing spectacles did not affect their chances in education (females $35 \%$ and males $47.1 \%$ ). Thirty-two per cent of the respondents believed that wearing spectacles reduced their chance of finding employment (males 33.3\% and females $30.8 \%$ ), and $45.2 \%$ of them believed wearing spectacles would not affect their opportunities for employment (males $47.6 \%$ and females $42.9 \%$ ). Interestingly, $27.1 \%$ of the students believed that wearing spectacles reduced their opportunities for marriage (females $29.0 \%$ and males $25.4 \%$ ), whereas half of the respondents believed that wearing spectacles would not affect their chances for marriage (males 54.5\% and 
TABLE 2: Attitudes and perceptions of the 387 students towards spectacle wear and eye care.

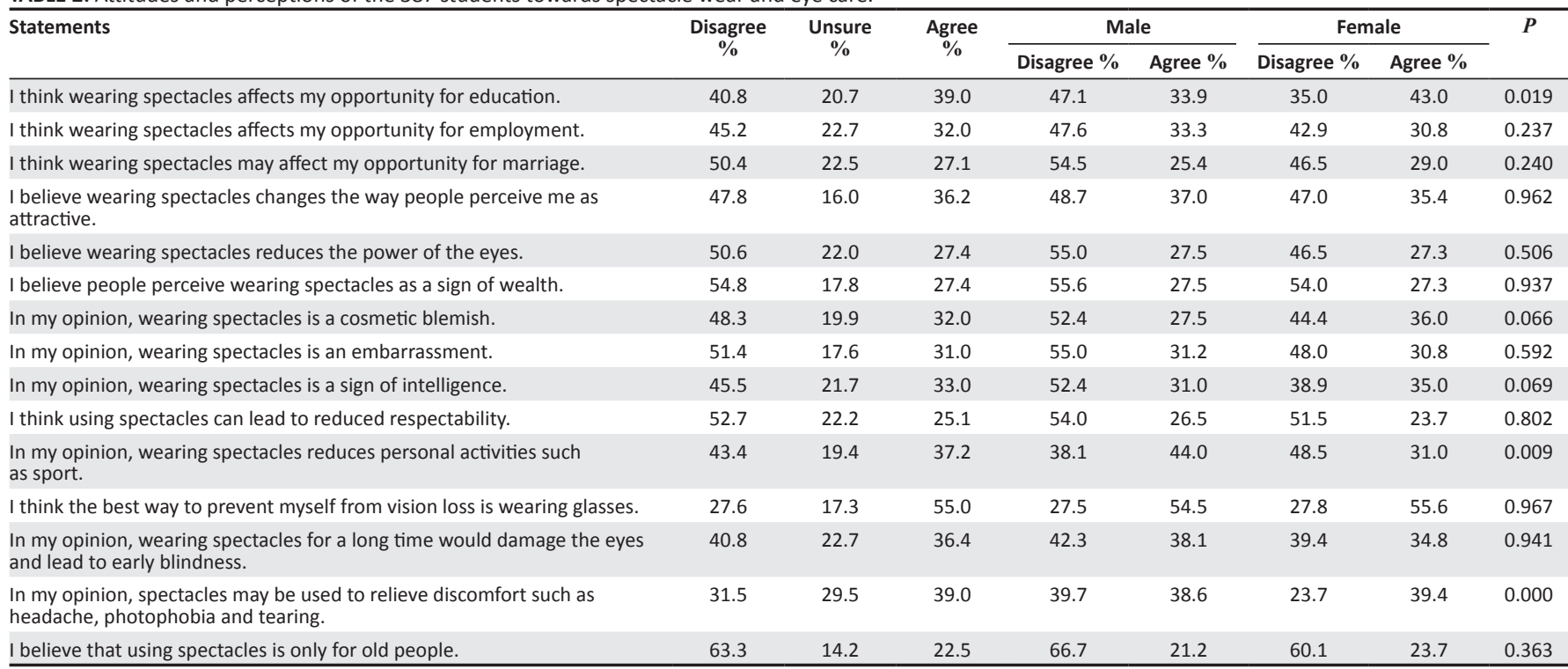

Note: These statements are translated from Arabic.

females $46.5 \%$ ). About $36.2 \%$ of the respondents in this study believed that wearing spectacles made them more attractive (males $37.0 \%$ and females $35.4 \%$ ), whereas $47.8 \%$ of them felt that wearing spectacles made them less attractive (males $48.7 \%$ and females $47 \%$ ).

On the question regarding wearing spectacles for treatment of refractive error, $27.4 \%$ of the respondents believed that wearing spectacles would reduce the power of the eyes (make the eyes weaker), but $50.6 \%$ of respondents believed that wearing spectacles would not make their eyes weaker. In addition, $27.4 \%$ of the students believed that wearing spectacles changed their appearance, making them appear richer, whereas $54 \%$ of the participants believed that wearing spectacles does not make them appear richer. Thirty-two per cent of the participants felt that wearing glasses was a cosmetic blemish (36.0\% females and $27.5 \%$ males) and $48.3 \%$ of them believed that wearing spectacles was not a cosmetic blemish (52.4\% males and $44.4 \%$ females). Thirty-one per cent of the students felt that wearing spectacles was embarrassing, whereas just over half of them (51.4\%) felt that wearing spectacles was not embarrassing. However, 33.0\% of the respondents believed that wearing spectacles was a sign of intelligence - the population of females who believed this (35\%) was slightly more than males $(31.0 \%)$ - whereas $45.5 \%$ of respondents did not believe that wearing spectacles was a sign of intelligence (males $52.4 \%$ and females $38.9 \%$ ).

Of the participants, $25 \%$ felt that wearing spectacles would lead to reduced respectability (26.5\% males and $23.7 \%$ females) and $52.7 \%$ of them thought that wearing spectacles would not affect their respectability (males $54.0 \%$ and females $51.5 \%$ ). Thirty-seven per cent of the respondents agreed that wearing spectacles affected their sporting activities (males $44.0 \%$ and females $31.0 \%$ ), and $43.4 \%$ of them disagreed that wearing spectacles reduced their sporting activities (48.5\% females and $38.1 \%$ males). Fifty-five per cent of the respondents agreed that using spectacles would prevent vision loss, and just over a quarter (28.0\%) disagreed that using spectacles would prevent vision loss.

About $36.4 \%$ of the respondents believed that using spectacles for a long time would damage their eyes and lead to early blindness (38.1\% males and $34.8 \%$ females). Fortyone per cent of respondents disagreed that wearing spectacles would damage their eyes and lead to early blindness (42.3\% males and 39.4\% females). Thirty-nine per cent of the respondents disagreed that spectacles would relieve discomfort such as headache, photophobia and tearing, and $31.5 \%$ of them agreed that spectacles would relieve such discomfort. A total of $22.5 \%$ of the participants believed that the use of spectacles was only for old people; the population of females who believed this $(24 \%)$ was slightly more than males $(21.2 \%)$. Sixty-three per cent of respondents disagreed that spectacles were only for old people $(66.7 \%$ males and $60.1 \%$ females $)$.

\section{Qualitative results}

\section{Parents' attitudes towards spectacle wear and eye care}

Parents were asked about the advantages and disadvantages of wearing spectacles (Table 3). Most of the parents (78.6\%) stated that the advantage of wearing spectacles was the improvement of sight as they were prescribed by the doctor. On the other hand parents saw the disadvantage of wearing spectacles as that they reduce the power of the eyes and furthermore spectacle wear had psychological effects, especially among females. The parents expressed the following (direct translation from Arabic):

'If the spectacles were prescribed by the doctor you also face a lot of challenges such as psychological and moral judgment from your family and friends. I have a daughter with spectacles, which she wears inside the house. When she wears the eyeglasses and walks in the street, she comes back home and complains of 
TABLE 3: Parents' attitudes and perceptions towards spectacles wear and eye care.

\begin{tabular}{|c|c|c|}
\hline Topics & Participants' responses & Percentage \\
\hline \multirow[t]{3}{*}{$\begin{array}{l}\text { What are the pros and } \\
\text { cons of wearing } \\
\text { spectacles? }\end{array}$} & $\begin{array}{l}\text { 1. If the spectacles were prescribed by the } \\
\text { doctor, then its advantage would be to } \\
\text { improve the sight. }\end{array}$ & 78.6 \\
\hline & 2. They will reduce the power of the eye. & 25.0 \\
\hline & $\begin{array}{l}\text { 3. The cons of wearing the spectacles are } \\
\text { they have moral and psychological effects, } \\
\text { especially among girls. }\end{array}$ & 14.3 \\
\hline $\begin{array}{l}\text { Do you think there is } \\
\text { any harm caused to } \\
\text { your child by NOT } \\
\text { wearing spectacles? }\end{array}$ & 1. His or her vision becomes worse. & 100.0 \\
\hline \multirow{2}{*}{$\begin{array}{l}\text { Do you think there is } \\
\text { any harm that may be } \\
\text { caused by wearing } \\
\text { spectacles? }\end{array}$} & $\begin{array}{l}\text { 1. If prescribed by a doctor, they will not lead } \\
\text { to any harm. }\end{array}$ & 57.1 \\
\hline & $\begin{array}{l}\text { 2. Wearing spectacles has social and } \\
\text { psychological effects on the child. }\end{array}$ & 10.7 \\
\hline \multirow[t]{4}{*}{$\begin{array}{l}\text { How would you feel if } \\
\text { your child had to wear } \\
\text { spectacles? }\end{array}$} & $\begin{array}{l}\text { 1. I feel that my child has lost an important } \\
\text { thing (asset) and the community sees him } \\
\text { or her as a handicapped person. }\end{array}$ & 18.0 \\
\hline & 2. I feel my child will become blind in future. & 10.7 \\
\hline & 3. I feel my child is visually handicapped. & 10.7 \\
\hline & 4. I feel my child has a dark future. & 10.7 \\
\hline
\end{tabular}

Note: These statements are translated from Arabic.

harassment as a result of using the spectacles.' (Focus group 6, participant 3, 43-year-old mother of schoolchild)

'Wearing spectacles have pros and cons. If someone has poor eyesight, spectacles improve the sight, and if the eyes are normal, this may lead to deterioration of the vision. I know a person with spectacles that were prescribed by the doctor and these spectacles reduced his vision and he became blind.' (Focus group 1, participant 5, 45-year-old father of schoolchild)

Overwhelmingly though, the parents agreed that if their children were not wearing the prescribed spectacles their vision would get worse. About 57.1\% of the parents reported that the spectacles, which were prescribed by the eye doctor, would not lead to any harm. However, almost $11 \%$ of the participants expressed that wearing spectacles has social and psychological effects on the children even if prescribed by the eye doctor. One parent expressed the following:

'Personally if there is another method of treatment I would choose it. However, I chose the spectacles for my child because there were no alternative methods for the treatment of poor eyesight.' (Focus group 1, participant 2, 37-year-old father of schoolchild)

Parents were asked about their feelings when their children were advised to wear spectacles to improve their vision. Many parents felt that their children had lost an important thing (asset) and that communities see them as a handicapped person. They felt their children would become blind in future and they felt concerned that their children could become visually handicapped and have a dark future. One parent commented the following:

'If the child is wearing eyeglasses the community looks at him/ her like they are a handicapped person. Especially, the girl's family is afraid of the possibility of getting married in the future because wearing spectacles is evidence that she is visually handicapped. Some families prevent their girls from wearing eyeglasses at social events such as at weddings etc. ...' (Focus group 7, participant 2, 51-year-old mother of schoolchild)

\section{Discussion}

\section{Quantitative study questions}

In this study, a significant percentage of respondents believed that wearing spectacles would affect their opportunities for education and employment. The population of males who felt that wearing spectacles was acceptable (47.1\%) was larger than females (35.0\%), which was statistically significant $(p=$ 0.019 ); this is in agreement with a previous study by Savur ${ }^{16}$ which indicated that $35 \%$ of females were teased for wearing spectacles. In this study, $27.1 \%$ of the students believed that using spectacles would affect their opportunity for marriage. Of these, 29\% were females and 25.4\% were males. These findings are similar to a study, which was conducted in India, where $31 \%$ of females stated that they were ready to hide their spectacles to avoid rejection before marriage. ${ }^{16,17}$ Moreover, another study, which was carried out among rural Indian students, revealed that $60 \%$ of respondents believed that one should not marry a spectacle-user. ${ }^{8}$

Almost $28 \%$ of respondents in this study believed that wearing spectacles would lead to weaker eyes. This result is similar to that found by Savur, ${ }^{16}$ where $30 \%$ of the participants believed that the continuous use of glasses would progressively increase their refractive errors. A significant percentage of the respondents believed that wearing spectacles was embarrassing and could lead to reduced respectability. Furthermore, the students believed that wearing spectacles was a cosmetic blemish, which was particularly expressed by the female respondents (36\%). These results are comparable to those found by Dhoble et al. ${ }^{8}$ who reported that one-third (32.0\%) of respondents felt that spectacles were cosmetically unacceptable and embarrassing in public - most of them were females. In our study, $37.2 \%$ of the students refused to wear spectacles because they affected their activities like sport. The percentage of males $(44.0 \%)$ was more than females $(31.0 \%)$, the difference being statiscally significant $(p=0.009)$. This may be because males are more likely to participate in sport (football) than females as well as cultural beliefs that may prevent women from participating in sport in these communities. This is in agreement with a study conducted in Pakistan in $20077^{18}$ where parents felt that spectacle wear hindered children's participation in sport and other extra-curricular activities.

In this study, $36.4 \%$ of the children believed that wearing spectacles for a long time would damage their eyes and could lead to early blindness, which is in agreement with the results of a study in Nigeria where $23.8 \%$ of respondents stated that spectacles would damage their eyes. ${ }^{17}$ An even greater number was found in another study which was conducted in Pakistan by Yasmin and Minto, ${ }^{18}$ where $69 \%$ of respondents believed that using spectacles would cause their vision to deteriorate. However, the perception of most of the students was positive about the use of spectacles to correct their vision and $55.0 \%$ of students in our study believed that the best way to protect the eyes from vision loss was by wearing spectacles. This is similar to a study conducted in Saudi Arabia, where $65 \%$ of the participants knew the importance of wearing spectacles. ${ }^{19}$ A significant percentage of students $(22.5 \%)$ 
believed that glasses were a method to enhance vision only for old people. This is also in line with the work of Ebeigbe et al. $^{10}$ who reported in Nigeria that $60 \%$ of respondents believed that glasses were meant for old people.

\section{Qualitative study questions}

In our study, most of the parents $(78.6 \%)$ indicated that the advantage of using spectacles was improving vision and the perceived disadvantage was that they make the eyes 'weaker' and they would have social and psychological impacts especially among females. In a study which was conducted in India by Senthilkumar et al., ${ }^{20}$ parents were aware that the wearing of spectacles improved distance and near vision. However, they avoided getting spectacles for refractive correction for a female because of cosmetic reasons. In this study, some parents expressed the view that they chose spectacles for the treatment of refractive error for their children because there were no alternative methods for correcting refractive error.

In a survey by Kodjebacheva et al. in southern California, ${ }^{21}$ participants experienced disappointment, unhappiness, worry and concern when they realised that they needed spectacles at a young age. Such reservations were also expressed by more than half of the parents in this study, who reported that if their children were advised to wear spectacles they felt that their children had lost an important thing and that the community would look at them as a handicapped person who could become blind in future.

The poor acceptance and the negative perception towards spectacles as the first-line method for treatment of poor eyesight by the communities in Sudan are of concern in addition to the established barriers for correcting childhood refractive error. There is a lack of health facilities as well as a lack of interventions by health care practitioners to influence the communities about using spectacles, to eliminate the social stigma towards spectacles wear, as well as a lack of health education programmes about the benefits of spectacles wear and the consequences of uncorrected refractive error.

\section{Conclusion}

The fear and stigma relating to the use of spectacles for eye care are widely experienced among students and their parents in Sudan, and particularly among females. It is suggested that during routine eye examinations, particularly in communities in developing countries, the practitioner should explain the advantage of wearing spectacles and emphasise the importance of glasses for the treatment of refractive error. This could lead to the elimination of the stigma and fear related to spectacle wear. In addition, education programmes through the mass media and schools, together with public presentations by eye care providers and psychologists, should be increased to address the misconceptions about spectacles. This study recommends the following:

- During eye examinations, optometrists or ophthalmologists should explain the advantages of wearing spectacles and emphasise the importance of spectacles for the treatment of refractive error.

- Education programmes through the mass media and schools, with public presentations by eye care providers and psychologists, are needed to address misconceptions about spectacle corrections.

- Celebrities and respected community individuals should be enlisted to wear spectacles and talk about the fashionable and trendsetting aspects of eyewear.

- Parents should be educated and counselled about the benefits of wearing spectacles and the possible consequences of not wearing spectacles regularly, such as the development of amblyopia and squint.

\section{Acknowledgements}

The authors would like to thank the school health promotion managers, Dr Jamal and Dr Adam Mousa, in South Darfur. They would also like to thank the data collection team, Mr Khalid and Miss Rwaa, for their hard work, and all the students and parents who participated in the study. This study was funded by the African Vision Research Institute (AVRI), and the researchers are grateful for the support of the Brien Holden Vision Institute.

\section{Competing interests}

The authors declare that they have no financial or personal relationships that may have inappropriately influenced them in writing this article.

\section{Authors' contributions}

S.H.A. was the project leader who was responsible for the experimental and project design under the supervision of P.C.C-F. and K.S.N. S.H.A. conducted all clinical research. P.C.C-F. and K.S.N. made conceptual contributions and provided guidance for the research. S.H.A. was responsible for the writing of the article with input and edits from P.C.C-F. and K.S.N.

\section{References}

1. Maritto SP. Global data on visual impairment 2010. WHO/NMH/PBD. Geneva: World Health Organization; 2012.

2. Johnstone P. Refractive error. London: Ninewells Hospital and Medical School; 2008.

3. Naidoo KS, Wallace DB, Holden BA, Minto H, Faal HB, Dube P. The challenge of uncorrected refractive error: Driving the agenda of the Durban declaration on refractive error and service development. Clin Exp Optom. 2010;193(3):131-136. https://doi.org/10.1111/j.1444-0938.2010.00455.x

4. Yu L, Li Z-K, Gao J-R, Liu J-R, Xu C-T. Epidemiology, genetics and treatments for myopia. Int J Ophthalmol. 2011;4(6):658-669. https://doi.org/10.3980/j. issn.2222-3959.2011.06.17

5. Naidoo KS, Leasher J, Bourne RR, et al. Global vision impairment and blindness due to uncorrected refractive error, 1990-2010. Optom Vision Sci. 2016:93(3): 227-234. https://doi.org/10.1097/OPX.0000000000000796

6. Naidoo KS, Jaggernath J. Uncorrected refractive errors. Indian J Ophthalmol. 2012;60(5):432-437. https://doi.org/10.4103/0301-4738.100543

7. Holden BA, Fricke TR, Wilson DA, et al. Global prevalence of myopia and high myopia and temporal trends from 2000 through 2050. Ophthalmology. 2016;123(5):1036-1042. https://doi.org/10.1016/j.ophtha.2016.01.006

8. Dhoble P, Agarwal R, Patel C, Anand G, Sharma J, Sabde Y. Study to assess the psychosocial aspects of refractive errors and effectiveness of health education in correcting stigmas related to spectacle use in high-school students of rural India. Int J Med Sci Public Health. 2013;2(3):716-719. https://doi.org/10.5455/ ijmsph.2013.060520131 
9. Holden BA. Uncorrected refractive error: The major and most easily avoidable cause of vision loss. Community Eye Health. 2007;120(63):37-39.

10. Ebeigbe JA, Kio F, Okafor LI. Attitude and beliefs of Nigerian undergraduates to spectacle wear. Ghana Med J. 2013;47(2):70-73.

11. Castanon Holguin AM, Congdon N, Patel N, et al. Factors associated with spectacle-wear compliance in school-aged Mexican children. Invest Ophthalmo Vis Sci. 2006;47(3):925-928. https://doi.org/10.1167/iovs.05-0895

12. Nyamai LA, Kanyata D, Njambi L, Njuguna M. Knowledge, attitude and practice on refractive error among students attending public high schools in Nairobi County JOECSA. 2016;20(1):35-41.

13. Alrasheed SH, Naidoo KS, Clarke-Farr PC. Prevalence of visual impairment and refractive error in school-aged children in South Darfur State of Sudan. Afr Vision Eye Health. 2016;75(1):273. https://doi.org/10.4102/aveh.v75i1.355

14. Alrasheed SH, Naidoo KS, Clarke-Farr PC. Childhood eye care services in South Darfur State of Sudan: Learner and parent perspectives. Afr Vision Eye Health. 2016;75(1):1-13. https://doi.org/10.4102/

15. Ismail KA, Khlafala F. Householders and housing characteristics 5 th population census 2008. Khartoum: Central Bureau of Statistics Census; 2008.
16. Savur S. The perceptions regarding refractive errors and their psychosocial impact on youth in Dakshina Kannada. J Clin Diagn Res. 2011:4(5): 746-748.

17. Ayanniyi AA, Olatunji FO, Mahmoud AO, Ayanniyi RO. Knowledge and attitude of guardians towards eye health of primary school pupils in Ilorin, Nigeria. Niger Postgrad Med J. 2010;17(1):1-5.

18. Yasmin S, Minto $\mathrm{H}$. Community perceptions of refractive errors in Pakistan. Community Eye Health. 2007;20(63):52-53.

19. Aldebasi Y. Young public's awareness to refractive error deficiency. Int J Health Sci. 2011;5(1):9-15.

20. Senthilkumar D, Balasubramaniam SM, Kumaran SE, Ramani KK. Parents' awareness and perception of children's eye diseases in Chennai, India. Optom Vision Sci. 2013;90(12):1462-1466. https://doi.org/10.1097/OPX.000 0000000000084

21. Kodjebacheva GD, Maliski S, Coleman AL. Use of eyeglasses among children in elementary school: Perceptions, behaviors, and interventions discussed by parents, school nurses, and teachers during focus groups. Am J Health Promot. 2015;29(5):324-331. https://doi.org/10.4278/ajhp.120315-QUAL-140 